\title{
Paleozoic cumaceans (Crustacea, Malacostraca, Peracarida) from North America
}

\author{
Frederick R. Schram ${ }^{1}$, Cees H.J. Hof ${ }^{2}$, Royal H. Mapes ${ }^{3}$ \& Polly Snowdon ${ }^{2}$ \\ ${ }^{I}$ Institute for Biodiversity and Ecosystem Dynamics, University of Amsterdam, Post Box 94766 , \\ 1090 GT Amsterdam, Netherlands, schram@science.uva.nl; ${ }^{2}$ Dept. of Earth Sciences, University of Bristol, \\ Bristol BS8 IRJ, UK, ${ }^{3}$ Dept. of Geological Sciences, Ohio University, Athens, Ohio 45701, USA, \\ e-mail: mapes@oak.cats.ohiou.edu
}

Keywords: Cumacea, North America, Paleozoic, Peracarida

\begin{abstract}
Three new species of malacostracans are described from North America in the Upper Mississippian Imo Formation of Arkansas, and the Pennsylvanian Eudora Shale of southeastern Kansas. These appear to be the oldest fossils attributed to the Cumacea and are only the third collection of fossil cumaceans anywhere to be described. Previously depicted forms occur in the Permian and Jurassic of Europe. We herein double the number of described fossil cumacean species and suggest some necessary adjustments to the higher taxonomy of the group to accommodate apomorphic features of the fossil and Recent forms.
\end{abstract}

\section{Contents}

Introduction

Localities and methods

Systematics

Neocumacea

Ophthalmcumacea

Ophthaldiastylis parvulorostrum

Carbocuma imoensis

Discussion

Securicaris spinosus

Acknowledgements

References

\section{Introduction}

The modern Cumacea are a very successful group of peracaridan malacostracan crustaceans with around 1215 species (Watling, pers. comm.). Nevertheless, until now only three species of fossil cumaceans have been described, despite the fact that these forms inhabit the fine sand and coarse silts perfect for fossilization (Schram, 1986). Bachmayer, (1960) recorded a poorly preserved cumacean-like specimen Palaéocuma hessi from the Callovian, Middle Jurassic, of France". Subsequently, Malzahn (1972) studied two well-preserved Permian species of the genus Opthalmdiastylis, $O$. inflata and $O$. costata, from the marl beds of Zechstein 1, Kamp-Lintfort, Germany. These latter taxa are noteworthy in that they exhibit distinctly lobed eyes, as the generic name implies.

This paper describes three new species of Carboniferous cumaceans from the Imo Formation (Upper Mississippian) of northwestern Arkansas, and the Eudora Shale (Pennsylvanian) of southeastern Kansas. Although our specimens are not as completely preserved as the Jurassic and Permian material, nonetheless, these Carboniferous species are clearly related to the younger specimens. We effectively extend the range for the Cumacea into a time frame for which we also have the earliest fossils for other peracaridan groups, viz., the Isopoda, Tanaidacea, Pygocephalomorpha, Lophogastrida, and Spelaeogriphacea.

\section{Localities and methods}

These specimens are in the fossil invertebrate collections of the San Diego Natural History Museum (SDSNH). Two localities are involved (Fig. 1).

SDNHM locality 3191: - Imo Formation, Upper Mississippian; Peyton Creek, Van Buren County, Arkansas. The outcrop is 


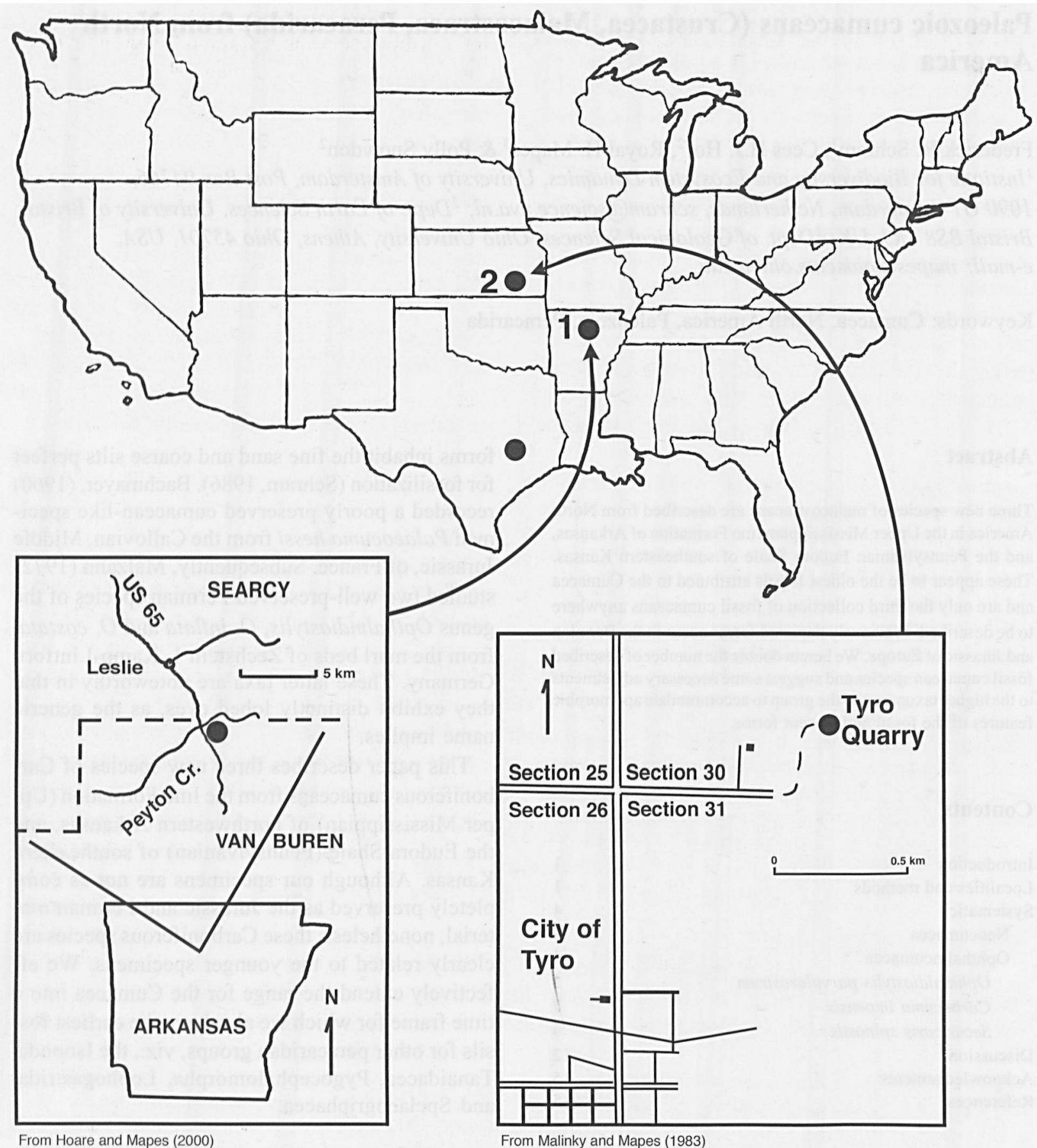

Fig. 1. Geographic information for cumacean localities. Site 1 (SDSNH locality 3191), Imo Formation., U. Miss; Peyton Creek, Van Buren Co., Arkansas; outcrop just south of the northern border of Van Buren Co., on US Highway 65, about $6.4 \mathrm{~km}$. southeast of Leslie, Searcy Co. (NE 1/4, sec. 11, T13N; R15W; Leslie 7 1/2 quadrangle). Site 2 (SDSNH locality 3267), Eudora Shale, Penn; Tyro Quarry, Montgomery Co., Kansas; 2.7 km. northeast of Tyro (NE 1/4, SE 1/4, sec. 30, T34S, R15E; Tyro $71 / 2$ Quadrangle). 
located just south of the Van Buren County border on the U.S. Highway 65 , about $6.4 \mathrm{~km}$ southeast of Leslie, Searcy County, Arkansas. Specimens were either collected on the surface or obtained from bulk samples that were not in situ.

The fauna is quite extensive. Schram and Mapes (1984) described a single carapace of a new genus and species of decapod crustacean, Imocaris tuberculata, from this site associated with a molluscan dominated fauna of ammonoids, gastropods and bivalves. Hoare and Mapes (2000) recorded a total of 49 taxa of ostracodes from the Imo Formation. Sohn (1940) listed 364 species representing 82 genera of Mississippian ostracodes. In addition, a variety of molluscs are known (Hoare et al., 1982, 1988, 1989; Hoare and Mapes, 1985; Jeffrey et al., 1994; Malinky and Mapes, 1983; Mapes, 1987; Mapes et al., 1986). On the basis of ammonoids (Saunders, 1973; Saunders and Work, 1999) the formation is dated to late Chesterian, Elviran Stage (E2b to E2b-c), equivalent to the Arnsbergian Stage in Europe.

The faunal composition of the Imo formation differs from that of the Chesterian faunas of the Appalachian and Eastern Interior. Webb and Sutherland (1993) show the laterally varying lithologies in a short distance of the Imo Formation and drastically different local environments. The invertebrate faunas previously described from the Peyton Creek road cut section indicate a general deepening of water in a relatively near shore marine environment. Also, there were fluctuations in the amount of terrigenous clastic deposit being deposited. At least 3 storm deposits have been observed in the section (Hoare and Mapes, 2000), and the diversity of ostracodes varied considerably between different levels within the formation, generally increasing from level 1 to level 5 .

Level I: Concretionary black shale. Assemblage dominated by the widespread platycopid ostracode, Cavellina, the dominance of which and the low diversity indicates an unstable, well-oxygenated, near-shore environment with much terrigenous clastic deposition. Common in this level are; articulated echinoderms, bivalves, gastropods, orthoconic cephalopods are common yet goniatite ammonoids are rare.

Level 2: Just below a crinozoan grain storm con- glomerate. Intermediate diversity between levels 1 and 3. Molluscs are less common than in level 1. Level 3: From the concretionary shale. The higher diversity and abundance of palaeocopid ostracodes indicates a shallow marine environment, somewhat further offshore and with more normal salinity than levels 1 and 2. Gastropods, bivalves, cephalopods (including goniatites) are common, but no echinoderms.

Level 4: From limey shale above the limestone. Most diverse fauna in this level, including the cumaceans in question. Assemblage indicates normal marine salinity, deeper water, more calcareous sediment with less terrigenous clastic additions in an offshore environment. Abundant bryozoans and echinoderms, but few cephalopods.

Level 5: From just below the limestone in limey shale. Diversity declines by more than $50 \%$ from Level 4. Lower diversity reflects the decline in calcareous*deposition with an increase in terrigenous clastics. Assemblage represents a shallow marine offshore environment. Salinity, water depth, substrate, depositional rate and temperature fluctuations all affected the faunal diversity.

SDNHM locality 3267: - Eudora Shale, Pennsylvanian; Tyro Quarry, Montgomery County, Kansas, Quarry is located 2.7 $\mathrm{km}$ northeast of Tyro, Montgomery County, Kansas.

The cumacean specimens came from the upper dark gray shale facies, thought to represent somewhat less oxygenated conditions than those of the underlying medium gray shales (Malinky and Mapes, 1982). The Eudora Shale is very fossiliferous. There is a highly diverse molluscan fauna, though only a few genera are common, with 9 genera of bivalves, and cephalopods, especially bactritoids (Mapes, 1979), while gastropods are less common. Scaphopods, rostroconchs and hyoliths are found even less frequently. For the most part the molluscs in their dark gray shale occur as pyritized internal moulds. Non-molluscan fossils are rare and include a few fragmentary sponges, bryozoa and brachiopods, echinoid fragments, crinoid columnals and blastoids, and lophophyllid corals. The microfauna includes conodonts, ostracodes and agglutinated foraminifers. Vertebrates are diverse and abundant as fragmented specimens in the phosphate nodule horizon at the base of the dark shale sequence, which 
probably represents a storm deposit. The faunal analysis of the facies by Malinky and Mapes (1982) indicates the upper dark shale bed was deposited in an oxygen-poor, normal marine, off-shore environment. The high organic content and total pyritization of the diverse fauna also indicates the dark gray facies was deposited under reduced oxygen levels. The gray and dark gray shale facies of the Eudora Shale, near Tyro, Kansas are similar to other Eudora Shale exposures in the region as indicated by common faunal elements including conodonts and crinoids.

The materials were generally studied initially under regular light microscopy. However, the small size of the specimens demanded SEM techniques for finer analysis. Both regular SEM and images were made using a low vacuum (variable pressure) SEM utilizing a back scattered electron detector (in our case a Robinson detector) were employed. In the latter, uncoated material can be safely examined (see Burnstock and Jones, 2000).

\section{Systematics}

Class Malacostraca Latreille, 1806

Superorder Peracarida, Calman, 1904

Order Hemicaridea Schram, 1981

Suborder Cumacea Kröyer, 1846

Infraorder Neocumacea, nov.

Diagnosis. - Eyes, when present at all, developed as an unpaired dorso-median organ fused to cephalothorax, generally without separate facets; pseudorostra and siphons well developed; ventral margin of carapace without medially directed shelf.

Remarks. - The distinctly apomorphic condition of the eyes and the development of the distinctive pseudorostrum and siphons, as opposed to what is seen in the Paleozoic forms, we believe necessitate the creation of a distinct infraorder to accommodate the living cumaceans. This infraorder should contain all the living cumaceans and should also include the Jurassic species Palaeocuma hessi Bachmeyer, 1960. Although the preservation of this Mesozoic form leaves a lot to be desired, we can see nothing that resembles the ventral brănchiostegal shelf characteristic of the Paleozoic taxa. Currently, 8 families of living cumaceans are recognized: Bodotriidae, Ceratocumatidae, Diastylidae, Gynodiastylidae, Lampropidae, Leuconidae, Nannastacidae, and Pseudocumatidae.

Infraorder Ophthalmcumacea Malzahn, 1972

Díagnosis. - Distinctly lobed eyes, free from cephalothorax, bearing well-developed facets; carapace lacking pseudorostra, but with anterolateral lappets extending forward; large ventral branchiostegal shelf providing a partial floor to branchial chamber.

Remarks. - Malzahn (1972: 448) used this taxon to accommodate cumaceans with lobed, well-facetted eyes, but he did not place it in opposition to any other taxon. The diagnostic characters used here, viz., the lobed eyes and lappets (which we believe are precursors of the pseudorostrum), are perhaps intermediate between generally plesiomorphic conditions (stalked eyes, carapace without lappets or pseudorostrum) and the states seen within the neocumaceans. In this respect, as Malzahn (1972) first pointed out, the evolution of cumaceans would seem to parallel that of the tanaidaceans (Schram et al., 1986) wherein the Paleozoic infraorder Anthracocaridomorpha is also predominantly characterized by the presence of intermediate characters such as lobed eyes. The ventral branchiostegal shelf of the ophthalcumaceans, however, is a unique apomorphic feature and apparently shared by all the Paleozoic forms.

Family Ophthalmdiastylidae Malzahn, 1972

Diagnosis. - As only one family is currently recognized, the diagnosis of the family is the same as that of the infraorder.

Type genus. - Ophthalmdiastylis Malzahn, 1972.

Remarks. - Malzahn (1972) did not formally designate or diagnose a family, but its status is implicit in his description of the species and use of the higher taxon name Ophthalmcumacea. 
Ophthalmdiastylis Malzahn, 1972

Diagnosis. - Rostrum wide and relatively long; pseudorostra very weakly, if at all, developed.

Type species. - Ophthalmdiastylis inflata Malzahn, 1972.

Remarks. - Malzahn (1972) did not clearly diagnose the genus. From the descriptions and illustrations it would appear that for both species of this genus a short, but true, rostrum characterizes $O$. inflata and $O$. costata. $O$. inflata appears distinguished by the smooth yet slightly papillose carapace, while $O$. costata is characterized by distinct longitudinal carinae on the carapace.

\section{Ophthalmdiastylis parvulorostrum new species Figs. 2, 3.1, 3.2, 5.1, 5.2}

Diagnosis. - Slender, somewhat laterally compressed carapace. Anteriorly serrate dorsal ridge extending longitudinally, terminating anteriorly in a slight frontal trough. Anterior lappets marked, extending slightly anteriad from the anterolateral edge of carapace lateral of the lobed eyes.

Description. - The carapace is about $1.3 \mathrm{~mm}$ in length. In dorsal view, the carapace is elongate and is somewhat pointed posteriorly. In lateral view, the carapace is ovoid, more constricted anteriorly. The height of the carapace is over $1 / 2$ the length and the transverse width is under $1 / 2$ that of the length. A reticulate sculpturing (Fig. 2.1) covers the carapace surface, which is characterized by irregular raised areas separated by narrow grooves. A mid-dorsal ridge is present, and this bears a set of 3 serrate teeth directed anteriorly (Figs. 2.1, 2.2). The tip of the short rostrum was equipped with 3 small spines (Figs. 2.3, 2.4); one can see their bases though the tips have broken off. One spine is terminal while the other two are located just posterior to it, one slightly in front of the other on the edges of the optic notches. A broad, ventral, branchiostegal shelf is present that extends the length of the carapace (29305, Fig. 2.5), There are no anterolateral spines, but the ventral shelf appears to merge smoothly into the anterior lappets (Figs. 2.1, 2.5). Ventrally, the carapace displays a narrow ventral ridge marking the bend that forms the branchiostegal shelf. The anterior lappets display a slight, spatulate form and extend anteriorly ventral and lateral to the compound eyes (Figs. 2.1, 2.2).

SDSNH 26273 shows a pair of large, well-preserved eyes protruding from beneath the frontal lobe and separated by a small rostrum (Figs. 2.2, 2.3, 2.4). The lobed eyes are equipped distally with a well-developed set of facets rounded to hexagonal in outline (Figs. 2.3, 2.4). The lobes themselves are decorated with a faint scale-like sculpturing (Figs. 2.3, 2.4).

Portions of endopods of thoracic limbs are preserved on SDSNH 26279 (Fig. 3.1). The details are obscure since the distal portions of the limbs are not preserved. The individual limbs are arranged parallel and appear to be remains of pereiopods, and if tentative comparison can be made to modern forms the appendages bore rather elongate bases (Fig. 3.2).

Etymology - A reference to the tiny rostrum.

Holotype. - SDSNH 26273 (Fig. 2.1 - 2.4). San Diego Natural History Museum.

Other material. - One fairly complete carapace paratype (SDSNH 29305); another partial specimen (SDSNH 26279); and a fragmentary and poorly preserved specimen (SDSNH 29309) tentatively assigned to this species as well.

Occurrence. - The holotype specimen and the questionable fragmentary specimen were collected from locality SDNHM 3191 in Arkansas. The paratypes (SDSNH 26279, 29305) was collected from locality SDNHM 3267 in Kansas.

Remarks. - The carapace of $O$. parvulorostrum is much more slender, elongated and laterally flattened than that of $C$. imoensis $\mathrm{n}$. sp., another cumacean from these same localities. $O$. parvulorostrum differs from O. inflata Malzahn, 1972 in its smooth carapace surface and smaller rostrum, and from $O$. costata Malzahn, 1972 by its lack of longitudinal carinae on the carapace. A reconstruction of $O$. parvulorostrum is offered in Figs. 5.1 and $\mathbf{5 . 2}$ 

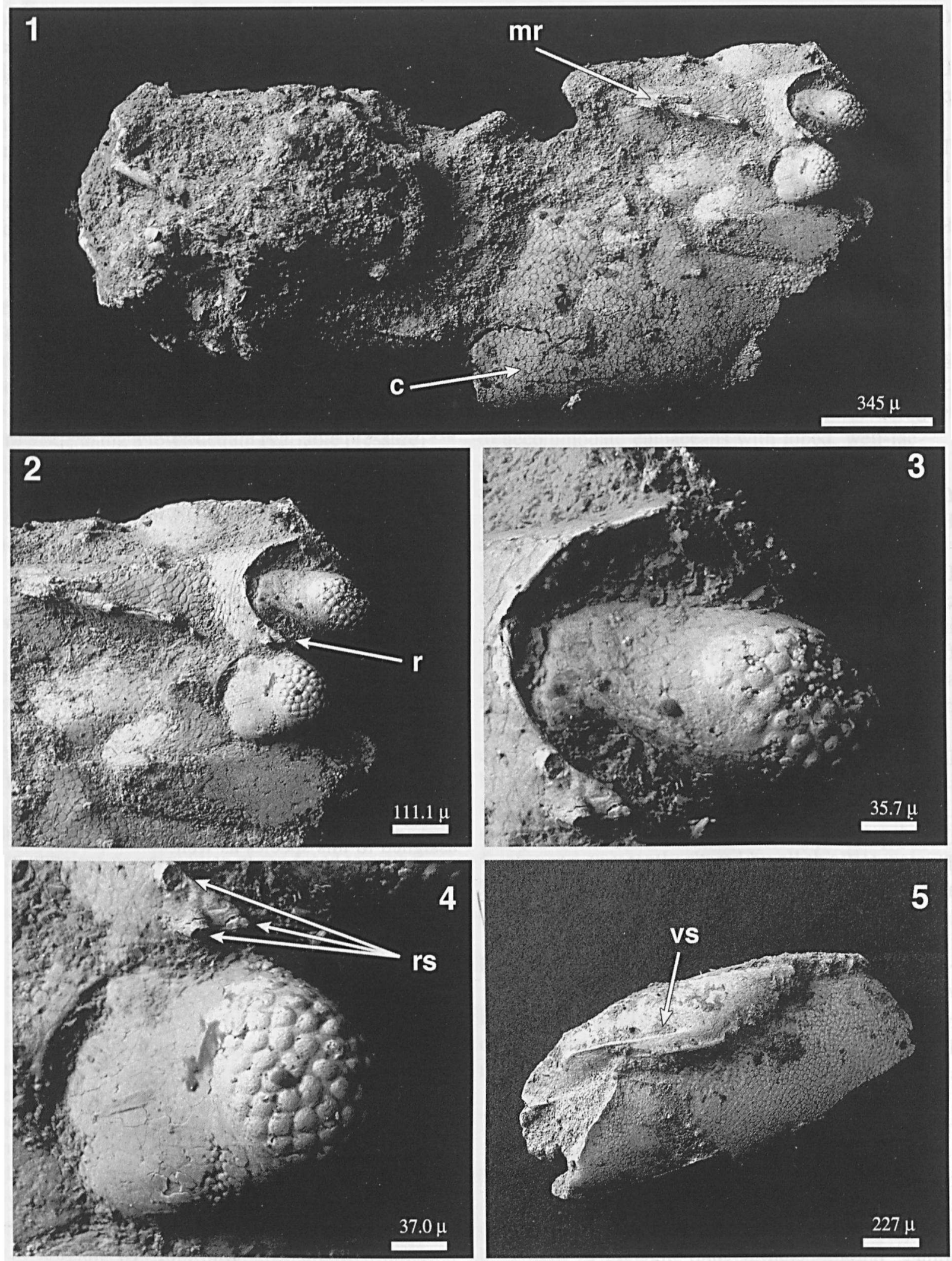


\section{Carbocuma new genus}

Diagnosis. - Carapace highly vaulted and barrellike, almost bulbous in lateral view. A deep middorsal trough runs longitudinally, and anteriorly expands to form a well-developed frontal lobe. A small rostrum is present. Small, sinuous lappets developed laterally. Well-developed lateral branchiostegal shelf on ventral aspect of carapace. Large, faceted, paired eyes.

Type species. - Carbocuma imoensis n. sp. by monotypy.

Etymology - Named after the Carboniferous period in which the fossils are found, and the genus Cuma, which was erected by $\mathrm{H}$. Milne Edwards and from which the name of the group Cumacea arises (Schram, 1986).

Remarks. - The relatively large size of the species along with the globose form and distinctive middorsal ridges and grooves justify a separate genus for this taxon.

\section{Carbocuma imoensis new species}

Figs. $3.3-3.6,5.3-5.5$.

Diagnosis. - As this taxon is monotypic, the diagnosis of the species is that same as that for the genus.

Description. - The approximate length of the carapace is $1.75 \mathrm{~mm}$. In dorsal view, the carapace is ovoid in outline, though complete posterior and anterior margins are not preserved together on the same specimen on any of the material at hand. In lateral view, the dorsal carapace is more rounded, although the ventral aspect is slightly flatter and has a bulbous mid-region that dips anteriorly into the frontal lobe (Fig. 3.3). The surface of the carapace is rather lightly textured with faint papillae, almost scale-like in places (Fig. 3.4, 3.5). The height of the carapace is roughly $4 / 5$ of the length, as is the transverse width. A deep median trough marks the dorsal surface of the carapace (Fig. 3.3) and is flanked by large, parallel ridges that bear less pronounced troughs on their crests. Wide mid-dorsal indentations extend from below the smaller troughs, anteriorly to spread around the frontal lobe, and ventrally to the mid-lower region of the carapace. . The frontal lobe itself is well developed and displays what appears to have been a small rostrum (Figs. 3.3, 3.4). A prominent ventral branchiostegal shelf extends the length of the carapace and is developed as a spine anteriorly, only the stump of which is typically preserved (Fig. 3.5). A distinct keel marks the point at which the branchiostegal shelf meets the side of the carapace, and similar narrow longitudinal ridges mark the interior edges of the shelf (Fig. 3.5). The ridges and lateral keels converge posteriorly, and anteriorly as well but to a lesser extent. The ventral margins of the carapace floor a large branchiostegal chamber and extend toward a mid ventral gap, with two smaller ridges along the margins adjacent to the gap (Fig. 3.5).

The holotype specimen, SDSNH 26275, preserves one large eye (Fig. 3.4). Its apparently short lobe bears a densely facetted field of ommatidia. Just ventral to the eyes, between them and the anteroventral spine, the margin of the carapace is developed as a somewhat sinuous, weakly developed set of lappets (Fig. 3.3, 3.4).

Specimen SDSNH 29308 illustrates preservation of pereiopods (Fig. 3.6). These are incomplete, but the elongate basis is virtually in tact and is marked by a scale-like cuticular decoration, not uncommon in living cumaceans too. Specimen SDSNH 29310 shows preservation of pereiopods and a faceted eye fragment.

Etymology. - The name imoensis is from the type locality of the specimen.

$\leftarrow$

Fig. 2. Ophthalmdiastylis parvulorostrum. 1-4, holotype, SDSNH 26273, 1. general dorsal aspect of specimen, note sculpturing on carapáce, 2. intermediate view of anterior end, 3-4, close-up views of left and right eye lobes, respectively, note scale-like ornament on lobes, 5, SDSNH26279, showing ventral aspect, specimen folded on itself. $\mathrm{c}=$ carapace, $\mathrm{mr}=$ median ridge, $\mathrm{r}+$ rostrum, $\mathrm{is}$ \% rostral spines, vs $=$ ventral shelf. 

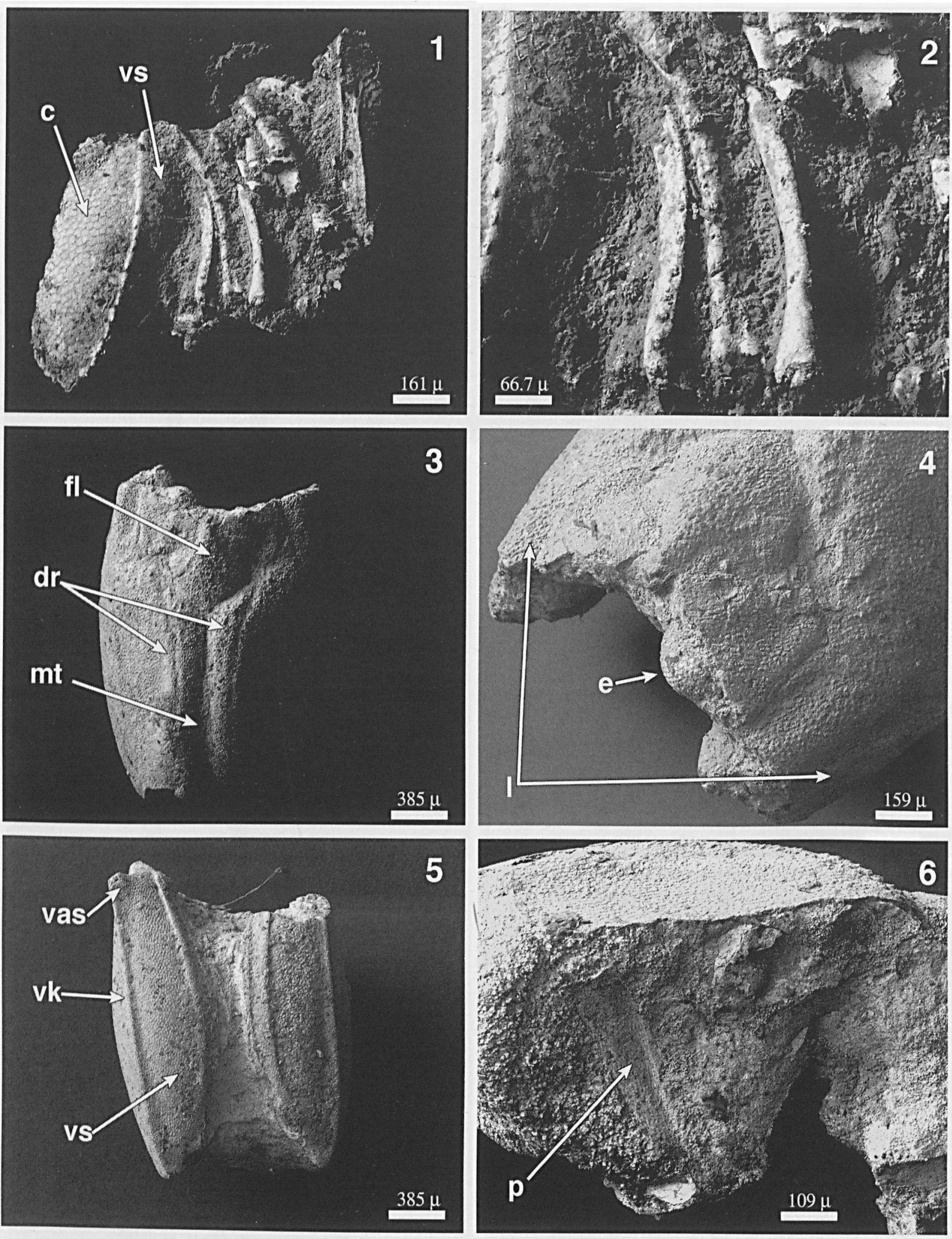
Holotype. - SDSNH 26275 (Figs. 3.2, 3.4). San Diego Natural History Museum.

Additional specimens. -'SDSNH 26274, 26277, 26278, 29307, and 29308. Another partial specimen, SDSNH 29310 is also tentative assigned to this species.

Occurrence. - SDSNH 26275 (the holotype) and SDSNH 26274, 26277, and 29308 come from locality SDNHM 3191 in Arkansas. SDSNH 26278, 29307, and 29310 come from locality SDNHM 3267 in Kansas.

Remarks. - This constitutes the most numerous and distinctive of cumacean species in these two localities. Reconstructions of the various views of the cephalothorax are provided in Figs. 5.3 to 5.5.

\section{Securicaris new genus}

Diagnosis. - Slender, laterally compressed carapace. Sharp dorsal ridge, anteriorly giving way to a relatively elongate and narrow frontal lobe almost $1 / 3$ the length of the carapace. Ventro-lateral ridge extends anteriorly to form large spine. Carapace decorated with a scale-like terracing.

Type species. - Securicaris spinosus n. sp. by monotypy.

Etymology. - From the Latin, securis (f.), meaning axe-like.

Remarks. - The rarest of the cumaceans reported herein, known from a single specimen. Though the specimen is incomplete, the sum of what is preserved seems to indicate that it is probably a cumacean. The general habitus accords with the other species described here, although it is unfortunate that only one specimen is at hand for study.
Securicaris spinosus new species

Figs 4.1, 4.2, 5.6, 5.7

Diagnosis. - Since there is but a single specimen, the diagnosis of the species is the same as that of the genus.

Description. - The fairly complete carapace is 1.5 $\mathrm{mm}$ in length. It is slender and elongate (Fig. 4.1). In lateral view the dorsal ridge is rather concave, more so than the ventral edge which is flatter. The height of the carapace is roughly $1 / 2$ that of the length, and the transverse width is just $1 / 3$ of the length. There is a sharp, narrow mid-dorsal ridge or crest, which flattens out anteriorly to form a triangular frontal lobe, widest at its most anterior end. A well-defined lateral ridge is present on the right-hand side and marks the transition to a ventral branchiostegal shelf. This lateral ridge extends anteriorly to form a rather delicate, well-developed, anterolateral spine, though the tip is absent. Ridge and spine are not preserved on the left-hand side. In ventral view, the ventral aspect of the left valve of the carapace is folded under the branchiostegal shelf of the right side, a vagary of the preservation of this specimen. The surface of the carapace between the mid-dorsal ridge and ventral keels is curved and decorated with a distinct scale-like sculpture creating the effect of overlapping terraces.

Etymology - A reference to the delicate anterolateral spine of the carapace.

Holotype. - The single known specimen, SDSNH 26276. (Fig. 4.1).

Occurrence. - The specimen was collected from locality SDNHM 3191 in Arkansas.

Remarks. - Though of similar size to Ophthalmdiastylus parvulorostrum, the carapace of S. spinosus appears to be more laterally flattened. The frontal

$\leftarrow$

Fig. 3. 1,2, Ophthalmdiastylis parvulorostrum, SDSNH 26279, 1, general ventral aspect, 2, close-up of pereiopods; 3-6, Carbocuma imoensis, 3,4, holotype, SDSNH 26275, note papillate sculpturing. on carapace, 5, SDSNH 29307, ventral aspect showing ventral shelf and mid-ventral gap into branchiostegal chamber, 6, SDSNH 2903, note sculpturing on long basis of pereiopod. $\mathrm{c}=$ carapace, $\mathrm{dr}=$ dorsal ridges, $\mathrm{fl}=$ frontal lobe, $\mathrm{l}=$ lappets, $\mathrm{mt}=$ median trough, $\mathrm{p}=$ pereiopod, vas $=$ ventro-anterior spine, $\mathrm{vk}=$ ventral keel, vs $=$ ventral shelf 

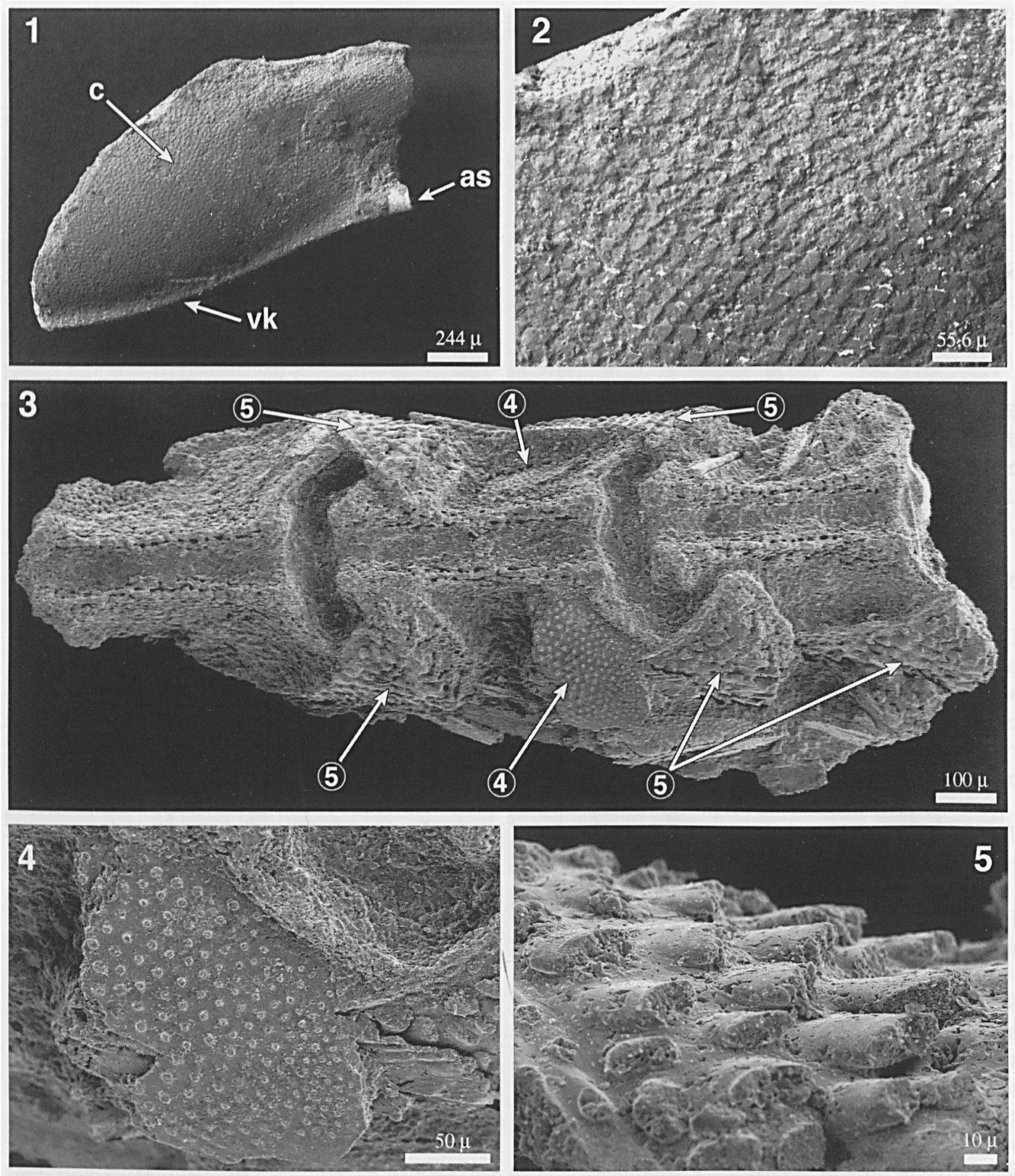

Fig. 4. 1,2, Securicaris spinosus, holotype SDSNH 26276; 1, general lateral view, 2, close-up of carapace cuticle; 3-5, SDSNH 29306,3 , dorsal aspect of one of three detached pleons referable to Cumacea, 4 and 5 key to the close-ups, $4-5$, patches of the pleonal cuticle of fig. 3 displaying the papillate (4) and scale-like(5) ornament. as $=$ anterior spine, $c=$ carapace, vk $=$ ventral keel, $4=$ designates areas with cuticle ornament as illustrated in fig. $4.4,5=$ designates areas with cuticle ornament as illustrated in fig. 4.5. 

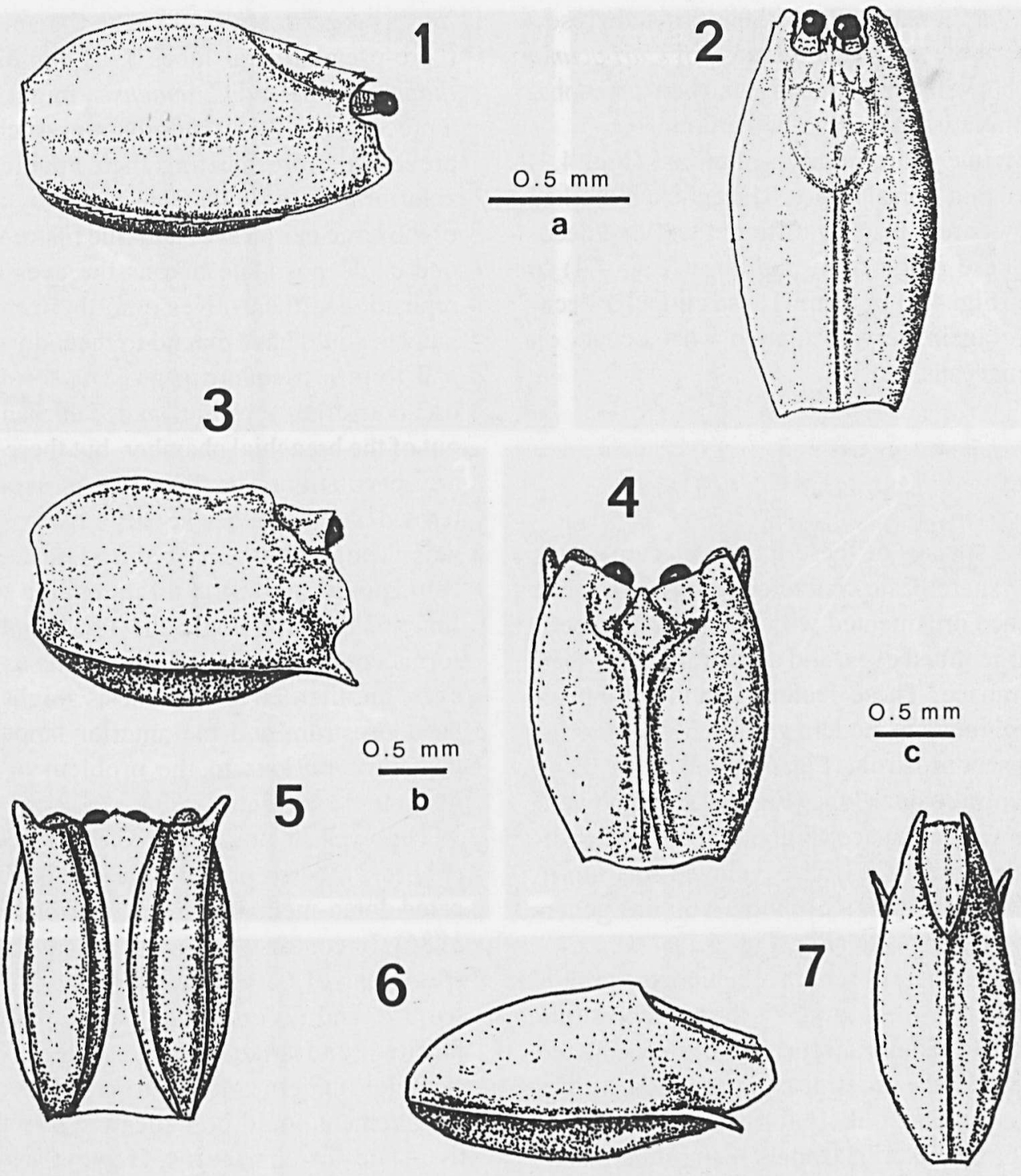

Fig. 5. Reconstructions of Paleozoic cumacean cephalothoraxes. 1-2, Ophthälmdiastylis parvulorostrum, lateral (1) and dorsal (2) views, scale a; 3-5, Carbocuma imoensis, lateral (3), dorsal (4), and ventral (5) views, scale b; 6-7, Securicaris spinosus, lateral (6) and dorsal (7) views, scale c.

lobe is narrower and longer than any of the other fossil cumaceans described herein, and there is a clear set of anterolateral spines that are lacking in Ophthalmdiastylus. The posterior dorsal area of the carapace on SDSNH 26276 does not seem to be complete, so the lateral outline as reconstructed (Fig. 5.6 ) is a surmise of the original form. Nevertheless, despite the singular and fragmentary nature of the specimen, all the features noted above justify the erection of a separate taxon.

\section{Cumacea sp.}

(Figs. 4.3-4.5)

Remarks. - In addition to the cephalothoracic material described and named above, the specimens at hand include three pleonal fragments (SDSNH 29310) that seem referable to the Cumacea (Fig. 4.3). These specimens are narrow and elongate consisting of 3 to 4 articulated segments and are virtually identical to the long, narrow pleons char- 
acteristic for Cumacea. From their size and preservation, these pleons might be those of Carbocuma imoensis, but without their being attached to a cephalothorax there is no way to be certain.

The specimens are highly sculptured (Fig. 4.3) with paired mid-dorsal ridges. The cuticle is marked with distinct areas bearing different textured decorations. These range from papillose (Fig. 4.4) to scale-like (Fig. 4.5) in form. These cuticular decorations are again very similar to what occurs on living cumaceans.

\section{Discussion}

Most of the species of these Paleozoic cumaceans apparently share basic characteristic features such as a carapace ornamented with spines and lappets, pairs of large lobed eyes, and a ventral lateral shelf on the carapace. These features stand in opposition to those found in modern groups. Modern forms display a pseudorostrum (Fig. 6.1, 6.2), a fused and reduced central ocular lobe (Fig. 6.2), and no ventral shelf on the carapace (Fig. 6.6.5, 6.6). In addition, the presence of a well-developed rostrum in $O$, parvulorostrum and $C$. imoensis is not generally seen in extant taxa (Fig. Fig. 6.1).

One feature that is absent in all Paleozoic groups yet present in all modern groups is the pseudorostrum (Fig. 6.1, 6.2). The pseudorostrum is a specialized development of the anterior carapace, and we believe that it was most likely formed by the medial extension of the anterior lappets seen in the Paleozoic species (Fig. 6.1, 6.2); it covers the anterior extension of the branchial cavity (McLaughlin, 1980). Whether the anterior lappets observed in these species is an actual evolutionary precursor to the pseudorostrum, or merely an analogous structure cannot be definitively determined at this point.

Assuming they are homologous, it is difficult to speculate about what might have encouraged the development of the anterior lappets of the carapace into a pseudorostrum. Though the anterior lappets ("pre-pseudorostral lobes"), as exhibited in Ophthalmdiastylis and C. imoensis, might appear to be a precursor to the pseudorõstrum, such lappets are prevented from meeting their counterpart dorsoanteriorly in the Paleozoic forms by the presence of the large paired eyes and true rostrum. Of course, one could postulate that as the eyes reduced and repositioned themselves onto the frontal lobe, the lappets could have extend to meet dorso-anteriorly and form a pseudorostrum. The formation of the pseudorostrum apparently aided in channeling water out of the branchial chamber, but these conclusions are speculation. The discovery of evolutionary intermediates between the large paired-eyed Paleozoic forms and modern reduced or eyeless species could possibly confirm this transition scenario, and functional morphologic and TEM studies of living forms could cast more light on this as well. However, an alternative hypothesis might be that the pseudorostrum and the anterior lappets are independent solutions to the problem of channeling respiratory currents.

The eyes in modern species of neocumaceans (Fig. 6-2), when present, are small, fused and located dorso-medially on the anterior lobe (Schram, 1986). In contrast, the eyes that can be seen in the specimens of $C$. imoensis, $O$. parvulorostrum, $O$. costata, and $O$. inflata are large, paĭred and well facetted, and arise from the anterior part of the cephalon underneath the frontal lobe. This latter arrangement could be indicative of a more primitive state for cumaceans. However, it is possible that the reduced eyes of modern forms also could have developed independently from the stalked eyes common in other malacostracans. In that case, the eye lobes in the fossils might represent an independently derived character state from the fused condition seen in living cumaceans.

Nevertheless, this reduction of either stalked or lobed eyes leading to the modern cumacean forms parallels what is known in the Tanaidacea, another

Fig.6. Diastylis cf. rathkei. 1 , left lateral view of carapace; 2 , dorsal view of pseudorostrum and optic lobe; 3 , ventral view of cephalothorax; 4, ventro-oblique view of posterior thorax showing relationship of pereiopods to posterior carapace margin, note long bases; 5 , ventro-oblique view of cephalothorax with posterior maxillipeds on right side removed to clearly display the ventral carapace margin, note lack of a distinct ventral shelf. $c=$ carapace, $c o=$ coxal openings of pereiopods, $b=$ basis of pereiopods, ol $=$ optic lobe, pr = pseudorostrum. 

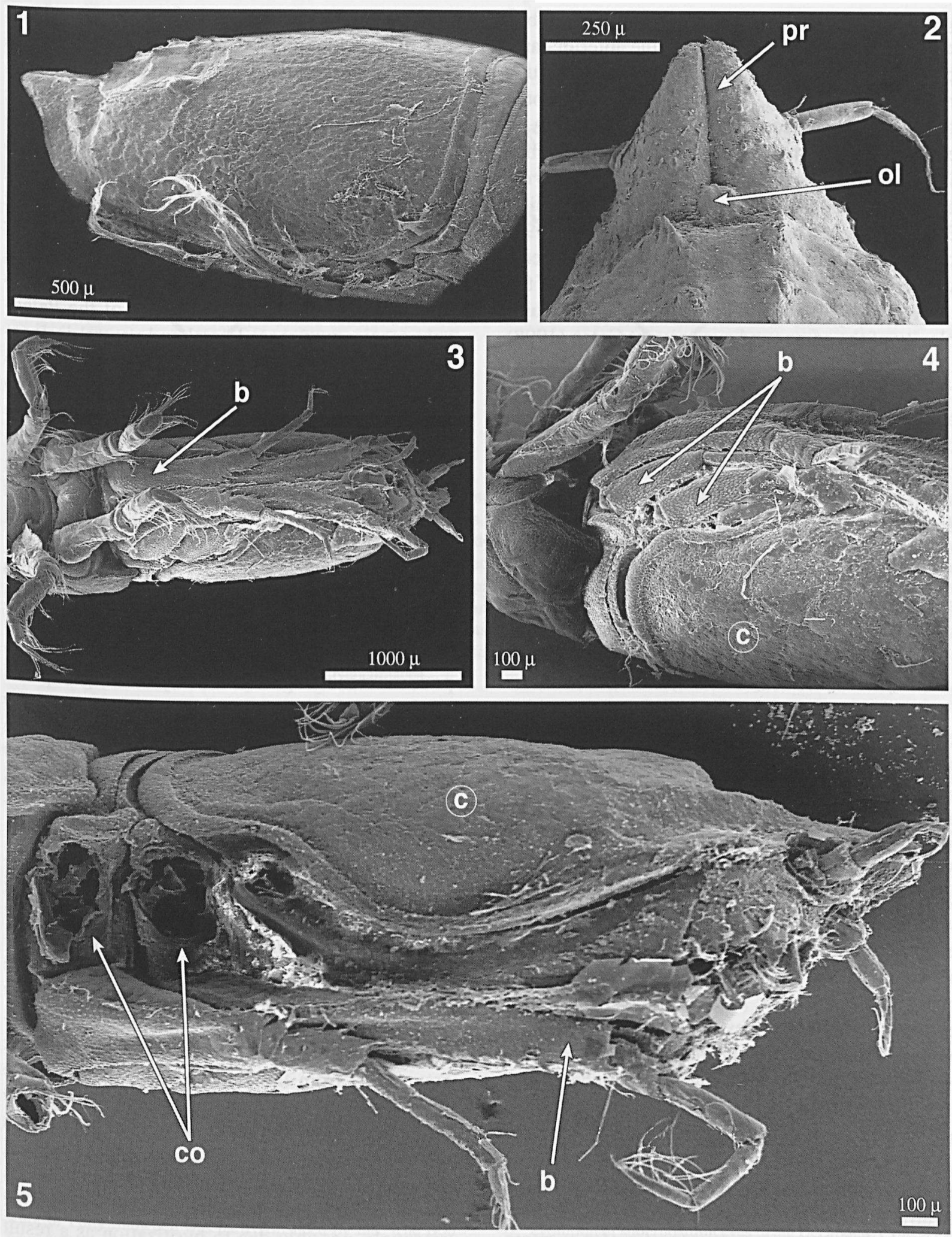
group whose Paleozoic forms also have large lobed eyes protruding from underneath the anterior carapace, while modern tanaidaceans possess much reduced eyes (Schram, 1986). Malzahn (1972) noted the Zechstein cumaceans had around 100 facets on each eye, and this number is approximately matched in the newly described forms $O$. parvulorostrum and $C$. imoensis. Modern species typically exhibit 3-4 facets, up to a maximum of 11. Gaten (1998) commented on the diversity of optical arrangements within the Crustacea, which display nine out of the ten types of described compound eye. The complexity of the compound eye brought Gaten (1998) to the conclusion that once an optical arrangement had evolved it would not be replaced by another arrangement unless it provided a significant optical advantage. The response of the eye, however, to adaptive pressures such as in those conditions that reduce the effectiveness of the eye, e.g., in burrowing, cave-dwelling or deep-sea crustaceans, results in evolutionary convergence. Interpreting the secondary reduction or loss of eyes in such species can be misleading and limits the use of eye structure in systematics (Gaten, 1998).

The tanaidaceans and cumaceans are sister groups within the Peracarida (Schram, 1986), and therefore it is not surprising that during peracaridan evolution the groups followed parallel evolutionary paths with respect to the reduction of the eye. Recent cumaceans are largely infaunal, and generally live just at or slightly below the surface of the sediment, with the pseudorostrum and frontal lobe exposed. The need for large eyes is low in this environment. The large eyes of the Paleozoic forms would have served well in a near-shore, marine environment with much available light. It might also be suggested that perhaps these Paleozoic forms had a more extended, pelagic aspect to their life cycles, and their larger eyes could have facilitated active swimming, and enhanced the visual detection of predators as well as mates. Details concerning the pereiopods and pleons of the Paleozoic species are needed for this hypothesis to be evaluated.

The ventral shelf on the carapace appears to be a unique structure. Modern cumaceans lack such an arrangement (Figs. 6.4, 6.5). This difference may bespeak different arrangements of water currents through and around the carapace branchial cham- ber. Modern cumaceans have a respiratory chamber that is dorso-lateral to the thoracic segments proper, the bulging upward of the carapace providing a space "above" the thorax, and movement of water within the chamber is facilitated by the beating of the epipodial bailers of the first maxillipeds. These in combination with the siphons that extend forward towards the pseudorostrum direct the flow of water out of the branchial chamber forward under the pseudorostrum. In the fossils, specimens like that seen in Fig. 3.6 would seem to indicate that the branchial chamber of the Paleozoic species was more lateral and ventral in location vis-a-vis the thorax proper. It is difficult to conceive how one arrangement could have lead to the other. Consequently, it is a viable alternative hypothesis that rather than the fossil condition serving as a precursor to the branchial arrangement seen in modern forms, these two conditions represent fundamentally different solutions to the functional constraints of respiratory currents in Cumacea.

The evolutionary history of the Cumacea is little understood, and the lack of preservation on these fossils of important characters such as mouthparts, attached pleonal regions, and details of the pereiopods makes the higher taxonomy of this group difficult. Nevertheless, it would seem clear that there are two major clades to be recognized within the group (Fig. 7). The Carboniferous ophthalmcumaceans may have formed in an intermediate stage to the living neocumaceans. However, it is equally likely that many of the features seen in the fossil ophthalmcumaceans could equally represent independent solutions to the problems of the evolving cumacean life style.

Assemblage information from the Imo Formation suggests that the Paleozoic cumaceans were living in a normal marine environment, slightly offshore and therefore deeper than the shallow marine fauna, with more calcareous sediment. The dark gray facies from the Eudora Shale in which the remaining specimens were found is also a very fossiliferous unit, and it is thought these cumaceans were also deposited in a off-shore, normal marine, yet very oxygen poor environment. These environments appear to have relatively good preservational potentials, possibly due to pyritization as a result of reduced oxygen conditions. It is very likely there- 


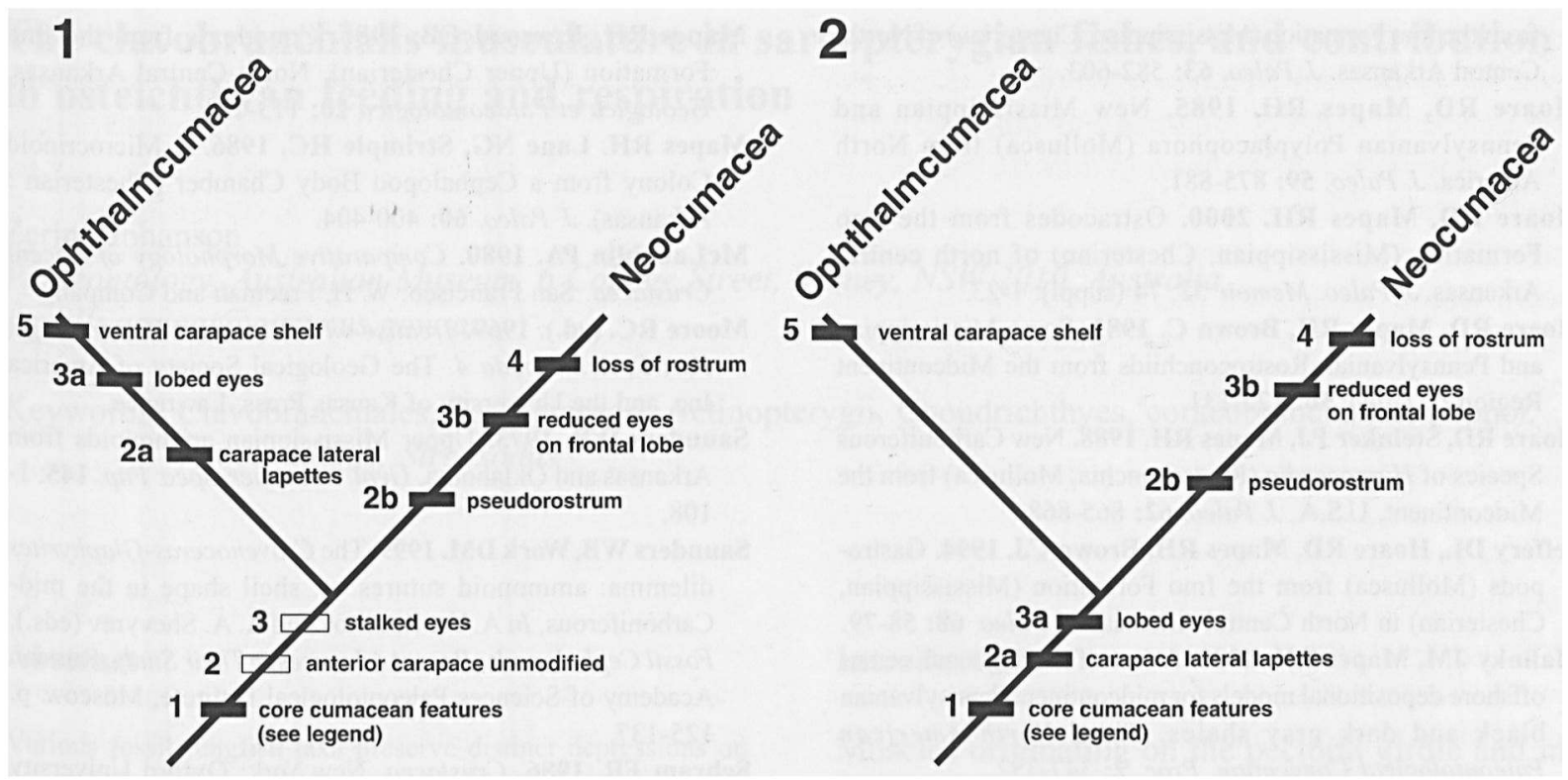

Fig. 7. Alternative phylograms of the Cumacea. Cumacea characterized by a core set of features (1), viz., posteriorly shortened carapace exposing 3-5 thoracic segments, 3 sets of maxillipeds, first maxilliped with multi-lobate epipodite, attenuated pleonal segments, and reduced or absent pleopods. 1, phylogram with independent development of lobed (Ophthalmcumacea), and reduced and sessile eyes (Neocumacea) from a plesiomorphic stalked condition, and a separate evolution of either lateral lappets (Ophthalmcumacea), or dorsal pseudorostrum (Neocumacea ) from a plesiomorphic carapace without any anterior extensions laterally or dorsally. 2, phylogram with lobed eyes (within the Cumacea) as an intermediate condition leading to reduced and sessile eyes on the frontal lobe (Neocumacea), and the development of lateral lappets (within the Cumacea) as a first stage towards the formation of a pseudorostrum (Neocumacea). In both, options, the ventral carapace shelf is an autapomorphy for the Ophthalmcumacea, and the loss of a true rostrum is an autapomorphy for the Neocumacea.

fore that many more fossil cumacean specimens could be found in these and similar localities of normal marine, offshore environments, though their small size inevitably inhibits their recognition.

This collection of North American fossil cumaceans doubles the number of previously known taxa and provides and extension of knowledge of this group from the Permian back into the Carboniferous.

\section{Acknowledgements}

We wish to thank Dr. Thomas Deméré, San Diego Natural History Museum, for allowing us to study this material, Dirk Platvoet, Zoological Museum, University of Amsterdam, for his help with SEM of living and fossil cumaceans, and Jan van Arkel, Institute for Biodiversity and Ecosystem Dynamics, University of Amsterdam, for assistance with the graphic design and layout. The work of Polly Snowden was partly financed by the "The Bob Savage Memorial Fund" of the University of Bristol. Low vacuum SEM images were made by Cees H.J. Hof financed by a European
Union Marie Curie Fellowship (Contract nr. ERBFMBICT 983257). Special thanks go to Dr. Chris G. Jones, Head of Electron Microscope Unit, Natural History Museum London, for providing the low vacuum SEM facilities and assistance. Dr. John Malinky helped process and sort the two metric tons of Eudora Shale from locality SDNHM 3267, and numerous students at Ohio University assisted in the collecting and processing of the more than four metric tons of the Imo shale; we thank these people for their assistance.

\section{References}

Bachmayer F. 1960. Eine fossile Cumaceenart (Crustacea: Malacostraca) aus dem Callovien von La Voulte-sur-Rhone (Ardéche) Ber. Schweiz. Pal. Ges. 53: 422-426.

Burnstock A, Jones C. 2000. Scanning electron microscopy techniques for imaging materials from paintings. In: Creagh DC, Bradley DA, eds. Radiation in Art and Archeometry. London: Elsevier, 202-231.

Gaten E. 1998. Optics and phylogeny: is there an insight? The evolution of superposition eyes in the Decapoda (Crustacea). Contrib. Zool. 67: 223-236.

Hoare RD, Heaney MJ, Mapes RH. 1989. Bivalves (Mollusca) 
from the Imo Formation (Mîssissîppian, Chesterian) of NorthCentral Arkansas. J. Paleo. 63: 582-603.

Hoare RD, Mapes RH. 1985. New Míssissippian and Pennsylvanian Polyplacophora (Mollusca) from North America. J. Paleo. 59: 875-881.

Hoare RD, Mapes RH. 2000. Ostracodes from the Imo Formation (Mississippian, Chesterian) of north central Arkansas. J, Paleo. Memoir 52, 74 (suppl); 1-23.

Hoare RD, Mapes RH, Brown C. 1982. Some Missíssippian and Pennsylvanian Rostroconchilids from the Midcontinent Region. J. Paleo. 56: 123-131.

Hoare RD, Steinker PJ, Mapes RH, 1988. New Carboniferous Species of Hippocardia (Rostroconchia, Mollusca) from the Midcontinent, U.S.A. J. Paleo, 62: 865-868.

Jeffery DL, Hoare RD, Mapes RH, Brown CJ. 1994. Gastropods (Mollusca) from the Imo Formation (Mississippian, Chesterian) in North Central Arkansas. J. Paleo. 68: 58-79.

Malinky JM, Mapes RH. 1982. A test of the lagoonal versus offshore depositional models for midcontinent Pennsylvanian black and dark gray shales. Third North American Paleontological Convention, Proc. 24 347-352.

Malinky JM, Mapes RH. 1983. First occurrences of Hyolitha (Mollusca) in the Pennsylvanian of North America. J. Paleo. 57: 347-353.

Malzahn E. 1972. Cumaceenfunde (Crustacea, Malacostraca) aus dem niederrheinischen Zechstein, Teil 1. Geol. Jahrb. 90: $441-462$.

Mapes RH. 1979. Carboniferous and Permian Bactritoìdea (Cephalopoda) in North America: University of Kansas Paleontological Contribution 64: 1-75, 41 pls.

Mapes RH. 1987. Upper Paleozoic Cephalopod Mandibles: Frequency of Occurrence, Modes of Preservation and Paleoecological Implications. $J$ Paleo. 61: 521-538.
Mapes RH, Rexroad CB. 1986. Conodonts from the Imo Formation (Upper Chesterian), North-Central Arkansas. Geologica et Palaeontologica 20: 113-123

Mapes RH. Lane NG, Strimple HC. 1986. A Microcrinoid Colony from a Cephalopod Body Chamber (Chesterian : Arkansas). J. Paleo. 60: 400-404.

MeLaughlin PA. 1980. Comparative Morphology of Recent Crustacea. San Francisco: W. H. Freeman and Company.

Moore RC. (ed.). 1969. Treatise on Invertebrate Paleontology, Part $R$, Arthropoda 4. The Geological Society of America Inc. and the University of Kansas Press, Lawrence.

Saunders WB. 1973. Upper Mississippian ammonoids from Arkansas and Oklahoma. Geol. Soc Amer. Spec. Pap. 145: 1108.

Saunders WB, Work DM. 1999. The Cravenoceras-Glaphyrites dilemma: ammonoid sutures vs. shell shape in the midCarboniferous, In A. Yu. Rozanov and A. A. Shevyrev (eds.), Fossil Cephalopods $\times$ Recent Advances in Their Study, Russian Academy of Sciences Paleontological Institute, Moscow. p. 125-137.

Schram FR. 1986. Crustacea. New York: Oxford University Press.

Schram FR, Sieg J, Malzahn E. 1986. Fossil Tanaidacea. Trans. San Diego Soc. Nat. Hist. 21: 127-144.

Schram FR, Mapes RH. 1984. Imocaris tuberculata, n. gen, n. sp. (Crustacea: Decapoda) from the upper Mississippian Imo Formation, Arkansas. Trans. San Diego Soc. Nat. Hist. 20: 165-168.

Sohn IG. 1940. Checklist of the Mississippian Ostracoda from North America. J. Paleo. 14: 154-163.

Accepted: 1 August 2002 